\title{
Humanização no cuidado de enfermagem: contribuição ao debate sobre a Política Nacional de Humanização
}

\author{
Humanization in nursing care: contribution to the discussion about the National Humanization Policy \\ Humanización en la atención de enfermería: contribuciones al debate sobre la \\ Política Nacional de Humanización
}

\begin{abstract}
Isis de Moraes Chernicharo', Fernanda Duarte da Silva de Freitas', Márcia de Assunção Ferreira"
' Universidade Federal do Rio de Janeiro, Escola de Enfermagem Anna Nery, Programa de Pós-Graduação em Enfermagem (Mestranda). Rio de Janeiro-RJ, Brasil.

"Universidade Federal do Rio de Janeiro, Escola de Enfermagem Anna Nery, Departamento de Enfermagem Fundamental, Programa de Pós-Graduação em Enfermagem. Rio de Janeiro-RJ, Brasil.
\end{abstract}

\author{
Submissão: 21-03-2012Ａprovação: 12-06-2013
}

\begin{abstract}
RESUMO
A pesquisa objetivou identificar e analisar os elementos que conformam as representações de profissionais de enfermagem e usuários sobre a humanização no cuidado; e discutir estratégias que contribuam para a implementação da Política Nacional de Humanização. Participaram doze profissionais que atuam no cuidado de enfermagem e quinze usuários adultos hospitalizados, todos da clínica médica de um hospital público, federal. Realizaram-se entrevistas semiestruturadas individuais, a que se aplicou posteriormente a técnica de análise temática de conteúdo. As concepções sobre humanização remetem às questões sociais, que mostram a relação entre o profissional e o usuário no cuidado; e gerenciais, que mostram as dificuldades e facilidades no âmbito assistencial para uma assistência humanizada. O debate com os sujeitos envolvidos no processo apresenta-se como estratégia para o alcance dos preceitos da Política Nacional de Humanização.

Descritores: Enfermagem; Humanização da Assistência; Políticas Públicas de Saúde.
\end{abstract}

\begin{abstract}
This research aimed to identify and analyze the elements that constitute the representations of nurses and users about the humanization of care, and to discuss strategies that can contribute to the implementation of the National Humanization Policy. Twelve professionals who were working effectively in nursing care and fifteen users hospitalized adults participated in the research, all of the medical clinic of a federal public hospital. Semi-structured individual interviews were used to generate data, to which the technique of thematic content analysis was applied. The conceptions about humanization refer to social issues, which show the relationship between professionals and users in nursing care; and, also, to management issues, which show the difficulties in health care facilities to obtain a humanized approach. The discussion with those involved in the process presents itself as a strategy for the scope of the precepts of the National Policy of Humanization. Key words: Nursing; Humanization of Assistance; Health Public Policy.
\end{abstract}

\section{RESUMEN}

Investigación cuyos objetivos fueron identificar y analizar los elementos que conforman las representaciones de profesionales de enfermería y usuarios sobre la humanización en la atención; y discutir estrategias que contribuyan para la implementación de la Política Nacional de Humanización. Participaron doce profesionales que actúan en la atención de enfermería y quince usuarios adultos hospitalizados, todos de la clínica médica de un hospital público, federal. Se realizaron entrevistas individuales semi estructuradas, a que se aplicó, después, técnicas de análisis temático de contenido. Las concepciones sobre humanización remeten a las cuestiones sociales, que muestran la relación entre el profesional y el usuario en la atención; y a cuestiones gerenciales, que muestran las dificultades y facilidades en el ámbito asistencial para una asistencia humanizada. El debate con los sujetos envueltos en el proceso se presenta como estrategia para el alcance de los preceptos de la Política Nacional de Humanización.

Palabras clave: Enfermería; Humanización de la Atención; Políticas Públicas de Salud. 


\section{INTRODUÇÃO}

Discutir a humanização na Enfermagem requer o entendimento de que este é um conceito ampliado que pode variar desde uma escuta atentiva, uma boa relação profissional-usuário, à reorganização dos processos de trabalho, a criação de ouvidorias e "balcões de acolhimento", até a melhoria das estruturas do serviço ${ }^{(1-3)}$. Para isso, torna-se imprescindível aprofundar essa discussão em uma visão integral e humanística, respeitando a individualidade, valorizando as crenças, atentando para a comunicação e estando presente na relação de cuidado, pois tudo isso são básicos na humanização ${ }^{(3)}$.

A humanização, abordada nesta pesquisa à luz das representações de profissionais de enfermagem e usuários, se ampara na concepção de que representações sociais (RS) expressam formas de conhecimento prático cujo principal propósito é orientar o sujeito a compreender e a comunicar-se no mundo. As RS trazem, em seu conteúdo, a dimensão cognitiva (conhecimento) e o afeto (intra-individual) do sujeito, tomando por referência o contexto no qual o indivíduo e seu grupo se inserem. É o binômio individual-social da representação que mostra ser esta potencialmente profícua para criar e transformar a realidade social ${ }^{(4-6)}$.

Na vivência dos processos sociais, no compartilhamento de saberes e ações, os sujeitos trocam informações, emitem opiniões e ajuízam sobre as coisas do cotidiano. Reelaboram ideias e imprimem mudanças e, com isso, organizam as suas concepções de mundo, identificando seus valores e a partir disso é que se torna possível um processo de desconstrução e reconstrução de saberes sobre o próprio sujeito e a sociedade.

Entretanto, transformar a cultura é uma tarefa extremamente complexa, visto que o campo cultural é influenciado por ideologias e na sociedade contemporânea, a ideologia capitalista enfatiza a individualidade, a competitividade, o consumo, o predomínio dos interesses materiais sobre os relacionais. Isto fragiliza a cultura coletiva, que envolve avanços e retrocessos, movimento de resistências e exigem análises críticas para posicionamentos mais assertivos sobre a representação de políticas, como a da humanização da saúde, e seus processos de implementação. Com a pretensão de produzir mudanças de cultura, faz-se necessário refletir criticamente sobre as concepções de humanização presentes na sociedade.

Torna-se, portanto, cada vez mais relevante o debate de tais questões entre alunos, usuários, profissionais e gestores da saúde, pois somente dessa forma será possível enraizar essas vertentes na sociedade contemporânea e erradicar concepções individualistas e práticas protocolares que nada contribuem para a humanização da assistência em saúde e, em especial, no recorte deste estudo, de enfermagem.

Em 2003 foi criada a Política Nacional de Humanização $(\mathrm{PNH})^{(7)}$, orientada pelos princípios da transversalidade (aumento da comunicação em cada grupo e entre os grupos), da indissociabilidade entre atenção e gestão, estímulo à autonomia e protagonismo de todos os partícipes (gestores, profissionais e usuários). Esta política foi pensada no sentido de se evidenciar a interface entre o cuidado e a gestão nos serviços de saúde, potencializando os que trabalham e os que utilizam os serviços de saúde como protagonistas e corresponsáveis pela produção de saúde.

Na enfermagem, a humanização toma proporções tanto no nível micro, relacionada à assistência, quanto no nível macro, da gestão e de políticas públicas, visto que, para se modificar a realidade, é necessário que se identifiquem obstáculos, presentes na área da saúde, que impeçam uma assistência digna e humana, cabendo a todos os partícipes a idealização e implementação de estratégias eficazes, tendo como meta uma assistência eficaz, resolutiva, de qualidade e humanizada.

Segundo a PNH, humanização é a valorização dos processos de mudança dos sujeitos na produção de saúde ${ }^{(7)}$. E esta humanização deve se expressar nas práticas dos serviços de saúde, "com os profissionais e usuários, de forma dialógica, em busca da construção de novos caminhos capazes de propiciar um novo paradigma de gestão da saúde pública para todos"(3).

Este estudo se justifica pelo próprio desafio que se apresenta no âmbito das práticas da PNH na construção de um caminho metodológico ${ }^{(8)}$ para a efetivação dos princípios desta política, ou seja, a lacuna que ainda se apresenta entre as diretrizes da política e a sua aplicabilidade na prática assistencial que deve estar amparado nas diferentes situações-problemas, assim como na diversidade dos próprios sujeitos na produção do cuidado em saúde. Para tal, a relevância deste estudo está na possibilidade de conhecer os saberes dos profissionais de enfermagem e dos usuários sobre o que vem sendo discutido e compreendido sobre a humanização, assim como o seu reflexo na prática assistencial, o que possibilita identificar a presença de lacunas na implementação da $\mathrm{PNH}$ nos serviços de saúde. Como as RS são entendidas como saberes práticos, conhecendo-as, é possível entender alguns dos impasses da implementação da PNH nas práticas de saúde.

À luz dessas questões, esse estudo tem como objetivos identificar e analisar os elementos que conformam as representações de profissionais de enfermagem e usuários sobre a temática da humanização no cuidado, assim como discutir a partir de tais resultados, estratégias que busquem aproximar cada vez mais essas questões visando como foco central a implementação efetiva da Política Nacional de Humanização (PNH).

\section{METODOLOGIA}

Pesquisa de natureza qualitativa de abordagem exploratória, do tipo descritiva, cujo referencial é o da Teoria das Representações Sociais (TRS) ${ }^{(4-6)}$. Investiu-se na busca de elementos constitutivos dos conteúdos das representações dos sujeitos sobre a humanização, a partir de suas experiências com o cuidado de enfermagem no campo hospitalar. A despeito de sua natureza qualitativa, dados quantitativos sobre os sujeitos serviram de apoio, subsidiando as discussões dos resultados, uma vez que à luz da TRS, as concepções dos sujeitos amparam-se na identidade dos grupos aos quais pertencem. A congregação dos dados quantitativos e qualitativos teve o intuito de zelar pela consistência dos achados.

A população deste estudo é constituída de profissionais de enfermagem (enfermeiros, técnicos e auxiliares de enfermagem) de um hospital universitário, público, federal e de 
usuários adultos hospitalizados no setor de clínica médica do referido hospital. Optou-se pelo setor de clínica médica por este ter um número significativo de usuários em tratamento prolongado e em condições clínicas que permitissem a produção dos dados da pesquisa.

Os critérios de inclusão para os profissionais foram: ambos os sexos, que atuem efetivamente no cuidado aos usuários hospitalizados nos setores de clínica médica, em qualquer turno (manhã, tarde ou noite). Como critérios de exclusão foram aplicados os seguintes: os sujeitos em atividades exclusivas de gerência, ou afastados da assistência por licença, de qualquer natureza, ou gozo de férias no período delimitado para a produção dos dados. De um total de 30 profissionais que trabalham neste setor, 19 atenderam aos critérios de inclusão, porém apenas 12 aceitaram participar da pesquisa.

A escolha dos usuários se baseou na aplicação dos seguintes critérios de inclusão: usuários adultos hospitalizados, de ambos os sexos. No período de execução da pesquisa, deveriam estar lúcidos e orientados no tempo e no espaço, e com a comunicação verbal preservada. Como critérios de exclusão aplicaram-se: ter comprometimento cognitivo, de consciência ou de comunicação verbal, que impedisse o diálogo e a realização das entrevistas, estarem com patologias que exigissem isolamento de contato ou respiratório. De um total de 38 usuários hospitalizados neste setor, 27 atenderam aos critérios de inclusão, porém apenas 15 aceitaram participar da pesquisa.

Os dados foram produzidos nos meses de fevereiro, setembro e outubro de 2010, com aplicação das técnicas de entrevistas individuais, seguindo um roteiro semiestruturado compostos de duas partes. Na primeira, constam perguntas sobre o perfil sócio demográfico dos sujeitos, que se impõe ao referencial teórico-conceitual adotado, pois se faz necessário traçar as condições de produção das ideias e concepções dos sujeitos uma vez que estas se assentam nas marcas de pertença e de suas identidades socioculturais. Na segunda parte, constam perguntas abertas nas quais os sujeitos foram solicitados a produzirem um discurso sobre as suas práticas no intuito de fazer emergir seus saberes e vivências sobre a humanização, a partir de cenas concretas de cuidado dos quais participaram.

Para a análise do material utilizaram-se técnicas de análise de duas naturezas: quantitativa, com aplicação de recursos da estatística simples e percentual aos dados oriundos da primeira parte do instrumento; e qualitativa, com aplicação dos recursos das técnicas de análise temática de conteúdo ${ }^{(9)}$, aos dados oriundos das questões abertas.

Em atendimento à Resolução $n^{\circ}$ 196/96 do Conselho Nacional de Saúde, o projeto de pesquisa foi aprovado no Comitê de Ética e Pesquisa da Escola de Enfermagem Anna Nery, da Universidade Federal do Rio de Janeiro, protocolo $\mathrm{n}^{\circ}$ 098/2009. O Termo de Consentimento foi assinado por todos os sujeitos. A identificação dos sujeitos foi alfanumérica, cuja letra $\mathrm{P}$ significa profissionais, $\mathrm{U}$ significa usuário, a letra $M$ significa masculino e a letra $F$ feminino, seguidos de números arábicos que indicam a idade dos sujeitos, com hífen separando o número indicativo da sequência de realização da entrevista.

\section{APRESENTAÇÃO E DISCUSSÃO DOS RESULTADOS}

\section{A. Características gerais dos sujeitos}

Dos 27 sujeitos que participaram dessa pesquisa, 19 eram do sexo feminino e 08 do sexo masculino. De acordo com o gráfico 1, a idade dos profissionais variou de 21 a 64 anos, concentrando-se na faixa de 43 a 53 anos. A dos usuários variou entre 21 e 65 anos ou mais, concentrando-se na faixa de 43 a 64 anos de idade.

Gráfico 1 - Distribuição dos sujeitos segundo a faixa-etária.

\section{USUÁRIOS PROFISSIONAIS}

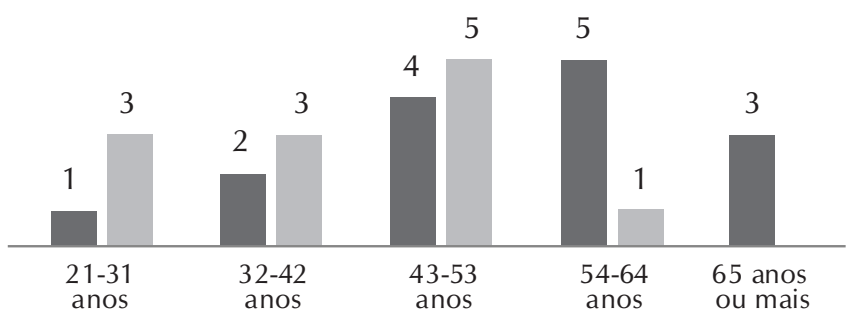

Na totalidade, a nacionalidade é brasileira, e tanto profissionais quanto usuários eram oriundos da região sudeste e nordeste do Brasil, com a maioria se concentrando no Rio de Janeiro $(70 \%)$. O estado civil caracterizou-se em sua maioria à situação de casado $(48,14 \%)$, seguido de solteiro $(33,33 \%)$, separado ou divorciado (3,71\% cada) e viúvo $(11,11 \%)$. Do total de sujeitos, 13 declararam-se católicos, quatro declaram ser espíritas; sete indivíduos declararam ser evangélicos, um é Testemunha de Jeová e dois não têm religião.

A renda familiar dos profissionais compreende desde dois até vinte salários mínimos. Dos 12 profissionais, oito têm casa própria e carro. O tempo de formação desses sujeitos correspondeu desde um a 12 anos de formação. O perfil econômico dos usuários caracterizou-se, em sua maioria, pela renda familiar entre um e dois salários mínimos (40\%) e pela moradia ser própria $(73,34 \%)$.

\section{B. Categorias temáticas}

Sobre os dados oriundos da análise temática de conteúdo, os elementos constitutivos das representações dos sujeitos sobre a humanização se organizaram em torno de três categorias: 1) Relação profissional/usuário como elemento para humanização da assistência; 2) Qualidade no atendimento e expressões humanizantes: recursos humanos/materiais e a instituição; 3) O cuidado como elemento inerente à humanização da assistência.

\section{Relação profissional/usuário como elemento para huma- nização da assistência}

Essa categoria emergiu com muita incidência, tanto no discurso dos profissionais quanto dos usuários, se estabelecendo através das vertentes da comunicação/diálogo e da empatia, em co-ocorrência com a relação profissional-usuário. 
A comunicação conduz o processo de cuidar, pois é a partir da utilização desse meio que se torna possível identificar, analisar, compreender e repassar a situação na qual o indivíduo está inserido, possibilitando a construção de estratégias peculiares a cada situação-problema ${ }^{(10)}$. A comunicação faz com que as idéias circulem, promove o diálogo e a interação. Ao se comunicarem, os sujeitos têm a possibilidade de se posicionar frente a um tema, debater, concordar, criar controvérsias, partilhar conhecimentos, o que permite ao indivíduo compreender o mundo e caminhar nele ${ }^{(6)}$. São através das conversações (e de outras circunstâncias também) que se elaboram os saberes populares e o senso comum. Por isso a comunicação é um elemento central na formação de RS. Destaca-se que a comunicação é importante na construção de saberes e práticas e, portanto, precisa ser clara, concisa e reciproca, visando o entendimento absoluto da mensagem transmitida, sem entrar nos vieses da interpretação ${ }^{(10)}$, situação esta que emerge dos discursos tanto dos usuários quanto dos profissionais de enfermagem.

Ainda mais, se ressalta que o diálogo e o entendimento da informação pelos usuários são indicativos de um atendimento de qualidade nos serviços, pois os conduzem a melhor discutir suas situações de saúde ${ }^{(11)}$.

A senhora em frente ficou na quarentena (referindo-se ao isolamento de contato) [...]. Então passaram uma coisa muito ruim dela. As meninas não podiam nem chegar perto dela. Até que eu cheguei no médico, o médico me explicou, nós entendemos e parou aquele pavor que estava tendo (UF59-01).

Por exemplo, a colega... a vizinha estava chorando... cheguei perto da cama e ela (uma profissional de enfermagem) mandou eu voltar pro meu leito para não contaminar o leito. Mas só que eu não estava em cima dela! Mas ela falou para o meu bem. Pro meu bem. Depois ela me explicou a situação e eu sei que tem que ser assim mesmo. Mas eu não tinha chegado perto não. Mas a gente fica meio constrangida (UF54-03).

Os usuários valorizam a comunicação efetiva, permitindo o estabelecimento de posturas, comportamentos e atitudes condizentes com uma unidade de saúde. Esta efetividade na comunicação possibilita que o indivíduo, ao se inserir em outro contexto, neste caso o hospitalar, compreenda como atuar neste cenário, agregando novos conhecimentos aos antigos e reformulando os modos de agir perante as novas situações. Por isso é importante captar conteúdos que conformam as RS das pessoas, pois não basta conhecer o que elas pensam e assimilam sobre um determinado tema, mas sim como agem perante a ele ${ }^{(12)}$.

O conteúdo presente na unidade de registro UF59-01, anteriormente transcrita, mostra bem a questão do contágio que tanto pavor causa, interditando as relações através de comportamentos significantes que denotam como os saberes sociais se engendram na conformação das práticas, levando ao afastamento ou a aproximação, que acabam por orientar, também, práticas no âmbito do cuidado de enfermagem ${ }^{(13)}$.
Nesta consideração, evidencia-se a importância de uma das dimensões das RS: a da informação. Na medida em que houve o encontro entre o saber do senso comum e o técnico-científico, através das explicações dadas pelo médico, houve um assentamento no comportamento da usuária. Esta é uma das funcionalidades das RS: levar o sujeito a melhor lidar com o que, para ele era desconhecido ${ }^{(4-6)}$.

O distanciamento entre o senso comum e o conhecimento científico, principalmente quando o indivíduo está inserido em um contexto assistencial, hospitalar, desencadeia sentimentos como o desamparo, ansiedade, estresse e medo com o que poderá lhe acontecer, acarretando diversas preocupações tanto para o próprio sujeito como para seus familiares, mantendo assim, uma posição submissa do cuidado por se sentirem em condições desiguais frente aos profissionais (tidos como os detentores do conhecimento científico) ${ }^{(14)}$. Para que isso não ocorra, a comunicação efetiva entre profissionais e usuários deve ocorrer, atendendo as expectativas de ambos os lados. Quando se há conhecimento dessas variáveis, os profissionais estarão aptos para proporcionar à família e ao usuário o acolhimento e o cuidado humanizado necessário ${ }^{(15-16)}$.

Na clinica médica eu vejo isso, eles têm muita carência de atenção. Aquela coisa de querer conversar e muitas das vezes você não pode fazer isso. Dá um pouco de frustação. O meu outro trabalho é em um posto de saúde. Eu acho que lá a gente pode ouvir mais... conversar. A escuta e o diálogo são coisas muito importantes (PF44- 08).

Assim como os usuários, os profissionais valorizam a comunicação, destacando um dos pontos chaves no processo de cuidar em enfermagem: a escuta atentiva, que vem ao encontro dos anseios e desejos do outro, criando vínculos solidários que contribuem efetivamente para a humanização no cuidado $^{(16)}$.

No conteúdo produzido pelos profissionais, identifica-se que a ideia sobre a humanização no cuidado está fortemente ligada às questões de empatia entre profissionais e usuários. Esta por sua vez, é um instrumento valioso no processo de humanização, visto que quando o indivíduo se coloca no lugar do próximo, quando pensa no que sentiria, se estivesse em situação vivida por outra pessoa, passa a agir de acordo com seus mais íntimos valores e ideais, qualificando o cuidado prestado.

Não sei, pra mim, o que me ajuda é sempre relacionar que pode ser minha mãe, pode ser meu pai ou pode ser qualquer pessoa que um dia vai precisar, pode ser eu, pode ser amanhã. Como eu quero ser cuidada? (PF35-05).

Porque eu trabalho com humanos assim como eu... E mesmo doentes eles merecem atenção e amor (PM24-01).

Os registros que caracterizam os depoimentos de profissionais de enfermagem vão ao encontro das concepções dos usuários que caracterizam as emoções, a afetividade como expressões humanizadoras da relação profissional-usuários. 
Olhar mesmo com carinho, dar atenção, conversar, ser mais sensível (UF43-05).

Tem muitos profissionais aqui bons, carinhosos, sabe? Trata a gente... Eu durmo bem quando eles estão no plantão (UF59-01).

Uma pessoa que entra sorrindo está nos dizendo algo, está dizendo que é acessível, que está aberta ao diálogo, as perguntas. É muito mais fácil, quanto mais para uma pessoa tímida, você ter acesso aquele profissional (UM50-04).

Identifica-se que os elementos que constituem a representação da humanização tanto para os profissionais quanto para os usuários se caracterizam na valorização das relações interpessoais baseadas no diálogo e nas questões subjetivas, os quais permitem uma aproximação entre eles que consequentemente auxilia no processo saúde-doença.

No entanto, para os sujeitos desta pesquisa a humanização no cuidado de enfermagem não se limita a tais questões, abrangendo também outras de cunho gerenciais que se configuram em obstáculos à aplicação dos preceitos da Política Nacional de Humanização.

\section{Qualidade no atendimento e expressões humanizantes:} recursos humanos/materiais e a instituição

Os profissionais de enfermagem, assim como qualquer profissional da área da saúde, para desenvolver seu trabalho de forma eficiente, atendendo aos seus objetivos e estimulando a população em busca de qualidade de vida, precisa de recursos apropriados ${ }^{(14)}$. Mas na realidade das práticas o trabaIhador se depara com inúmeros obstáculos em seu ambiente de trabalho, os quais se caracterizam nos resultados como aspectos que dificultam a aplicação de um cuidado mais humanizado, em co-ocorrência com a saúde do trabalhador que reflete fortemente na qualidade da assistência prestada.

Muitas vezes falta material para a gente trabalhar e isso dificulta muitas vezes. A gente tem que improvisar, fazer milagre... As condições de trabalho, de contrato de pessoal. Outro fator é a estrutura física do hospital (risos). Aqui era um setor interditado, ou seja, nós viemos para um setor que estava interditado, que tem condições precárias, pisos faltando, sabe? Por mais que você limpe, não fica limpo. Mobiliário antigo, desgastado, que não tem manutenção (PF35-11).

Há situações que desgastam o trabalhador, tais como a falta de materiais, mobiliário inadequado, o ritmo intenso de trabalho, além das longas jornadas de trabalho, ritmo mecânico do trabalho com repouso insuficiente e condições de trabalho que por si só tornam o ambiente de trabalho desumano(16-17). Para se ter uma assistência humanizada não basta apenas investir em equipamentos e tecnologias, mas deve-se investir também no acolhimento, baseado na comunicação/diálogo e respeito ${ }^{(15,18)}$. Para isso, torna-se necessário a humanização também nas condições de trabalho destes profissionais. Os funcionários que se sentem respeitados pela instituição prestam atendimento mais eficiente.

A Política Nacional de Humanização traz consigo o conceito de ambiência que se refere ao tratamento dado ao espaço físico, entendido como espaço social, profissional e de relações interpessoais, o qual deve proporcionar atenção acolhedora, resolutiva e humana(7). O que se deve analisar, a partir de tais pressupostos, é em que condições a equipe de enfermagem está trabalhando e em que proporções tais condições afetam a saúde do trabalhador e o cuidado por ele prestado? Em se tratando de RS, o contexto é o maior influenciador na construção e transformação das representações acerca de um objeto, ou seja, é no contexto em que o indivíduo está inserido que se irá estruturar o conhecimento e as atitudes e práticas frente ao objeto ${ }^{(12)}$. Se o contexto de trabalho é hostil, os pressupostos e dispositivos da PNH serão desacreditados, as conversações sobre sua inoperâncias estarão cada vez mais presentes no cotidiano e será mais difícil implementá-la, pois o senso comum sobre sua falência será formado entre os profissionais e os usuários, levando-os a uma naturalização sobre o caos. O contrário ocorre quando se tem uma gestão de recursos humanos e materiais que viabiliza o trabalho que gera satisfação profissional, levando a equipe à motivação e, consequentemente, a ações cada vez mais humanizantes.

Neste ínterim, identifica-se que tanto os profissionais quanto os usuários consideram que as condições de trabalho e o quantitativo de profissionais importam à humanização da assistência.

Ah... eu acho que poderia ter mais... profissionais (UF21-06).

Mais... mais condições de trabalho. Profissionais. Mais materiais de trabalho. Equipamentos. Acho que isso podia melhorar a assistência (UM50-04).

É interessante identificar que dos discursos dos usuários emerja a questão gerencial. Isto sinaliza que estes elementos integram não somente as concepções dos profissionais, mas também fazem parte das representações dos usuários acerca da humanização, compreendendo-a não somente em relação às questões inter-relacionais, mas incluindo também a situação institucional e a saúde do trabalhador. Isso indica que, para os usuários, as condições nas quais o profissional está inserido irão refletir no seu cuidado e, para tal, torna-se importante que esse trabalhador tenha condições adequadas para proporcionar um atendimento que vá ao encontro dos ideais de cuidado dos usuários.

Essas questões de gestão político-financeira, de infraestrutura, oferta da assistência, que envolvem tanto quantidade quanto qualidade dos recursos humanos e materiais, ainda se apresentam como uma barreira para se obter um cuidado humanizado ${ }^{(8)}$. Portanto, essa temática deve ser o enfoque central nas discussões não apenas de gestores, como também de trabalhadores e usuários da rede pública de saúde, compreendendo e internalizando o conceito de cuidado e humanização e sua relação com a enfermagem. 
$O$ cuidado como elemento inerente à humanização da assistência de enfermagem

O cuidado vem sendo discutido desde a década de 70 como um ideal filosófico. Abrangendo posteriormente conceitos amplos e diversos como a atenção, a cautela, o desvelo, o zelo; o ato de assistir, vigiar, ajudar; sendo mais do que um ato, uma atitude de ocupação, preocupação, responsabilidade e de envolvimento afetivo; como uma forma de ser; relacionado a sentimentos; como relação com outro ser humano e um estado que um sujeito reconhece a si mesmo em outro e conhece o outro e importa-se com ele; como processo interativo em três dimensões: pessoal, social e profissional e como um fenômeno moral|(19).

Este ideário está impregnado nas representações sobre a enfermagem e sua prática, o cuidado ${ }^{(14-16,19)}$, e aparece claramente situado nas representações dos profissionais.

A relação que eu faço é que não existe enfermagem sem humanização. São duas paralelas que andam praticamente juntas. E na minha cabeça não tem como diferenciar humanização e enfermagem. O cuidar é enfermagem. É uma coisa só. É única. Não tem como você pensar em enfermagem e não pensar em cuidado. O cuidado vem junto com humanização. Falar em humanização é falar de cuidar. Não tem forma de separar a humanização do cuidar (PF30-12).

A enfermagem é uma ciência que apresenta como essência e especificidade o cuidado ao ser humano, seja individualmente, na família ou em comunidade de modo integral e holístico, desenvolvendo de forma autônoma ou em equipe atividades de promoção, prevenção, proteção e reabilitação da saúde ${ }^{(19-20)}$.

O conceito de humanização agrega-se ao próprio conceito de cuidado, pois humanizar responde pela "convivialidade, solidariedade, irmandade, amor e respeito ao outro"(20:8). Como humanizar corresponde a cuidar/cuidado e a enfermagem tem no eixo de sua ação o cuidar, e esse traz no seu próprio conceito a perspectiva da humanização, logo se pode inferir que o cuidado humanizado está fortemente ligado a esta profissão. Portanto, integra o universo representacional de profissionais e de usuários.

Evidenciou-se nas representações dos profissionais e dos usuários, sobre a humanização no cuidado de enfermagem, a valorização da satisfação das necessidades com vistas ao bem-estar físico e emocional e das manifestações de atenção, carinho e paciência, associando-o à afetividade própria do ser humano. Nesse ínterim emerge uma das dimensões das representações sociais: a dimensão afetiva, pois quando os sujeitos sociais empenham-se em entender e dar sentido ao mundo, eles também o fazem com emoção, com sentimento e com paixão(4-6).

Quando você consegue agregar não só a parte física, mas a parte psicológica, emocional, prestar uma assistência em que ele se sinta seguro, isso é uma assistência humanizada. Tem que gostar. Não tem como... é o toque! Porque você tem que pegar na pessoa, você tem que conversar, tem que olhar no olho dela e como você vai fazer isso se você não gosta? (PF35-05).
Olha, o cuidado da enfermagem é o melhor possível. Elas têm bastante atenção com a gente. A gente pode confiar nelas que elas são de confiança, cuidam bem da gente, remédio na hora certa, se a gente chama, elas vêm, se a gente precisa, elas estão sempre ao nosso lado (UM44-01).

Essa relação interpessoal entre profissional e usuários que transpassa as barreiras criadas pelos próprios sujeitos como forma de proteção individual, é uma característica que nos afirma que é possível resgatar a humanização nas práticas assistenciais de enfermagem. A qualidade das relações humanas evidencia-se como elemento imprescindível ao alcance de preceitos da Política Nacional de Humanização ${ }^{(16)}$.

É possível tornar essa assistência algo além do técnico, do científico, que caminha ao encontro do subjetivo e da complexidade do ser. Permitindo, portanto, que a Política Nacional de Humanização não seja apenas uma política que ainda encontra dificuldades para estar presente em todo o contexto assistencial, mas sim uma política concreta, palpável, presente e insubstituível quando se fala de cuidado de enfermagem ${ }^{(8,14)}$.

A organização e discussão de tais categorias temáticas indicam que há três elementos chaves que se congregam na conformação das representações de profissionais e usuários sobre a humanização: as relações interpessoais entre eles, os recursos para a oferta dos serviços (humanos e materiais) e a própria natureza (humana) do cuidado de enfermagem.

Nesse sentido, a lógica de construção das ideias tanto dos profissionais de enfermagem quanto dos usuários sobre a humanização passa por questões tanto sociais, que mostram a relação entre o profissional e o usuário que viabiliza o cuidado, quanto gerenciais, que mostram as dificuldades e facilidades no âmbito assistencial para se obter uma assistência humanizada.

Portanto, se, à luz da TRS, a representação social é uma forma de conhecimento que se assenta na experiência/vivência e se reporta às práticas ${ }^{(4)}$, o esmero dos profissionais na assistência desvinculado das condições estruturais para a oferta dos serviços não se configura em uma assistência humanizada. Isto mostra que, tanto profissionais quanto os usuários estão cientes de que uma questão está intimamente ligada à outra, articulando os saberes sociais e os do universo da ciência.

\section{CONCLUSÃO}

Os conteúdos das representações sociais dos profissionais de enfermagem e dos usuários sobre a humanização do cuidado permeiam tanto as questões sociais (comunicação/diálogo, empatia, relação profissional/usuário) quanto às questões gerenciais (infraestrutura, materiais, recursos humanos), fazendo com que o fator humano nas relações interpessoais emerja como um importante indicador da qualidade da humanização no cuidado hospitalar.

Um critério importante para se avançar na implementação da Política Nacional de Humanização e assegurar qualidade e continuidade dos seus preceitos é o processo constante de avaliação institucional, ampliando e fomentando pesquisas que avaliem as seguintes condições: o campo da informação, da 
comunicação de massa, as questões éticas implicadas na garantia dos direitos dos pacientes, as condições de oferta dos serviços, o dimensionamento e a qualificação dos trabalhadores em face do quantitativo da clientela e da complexidade da assistência.

À luz de tais conteúdos de representação sobre a humanização, cabe aos gestores a análise minuciosa de cada questão que se apresenta como empecilho para a implantação uniforme e global da política, assim como cabe aos profissionais sinalizá-las de forma objetiva e embasada em seu cotidiano profissional. Estimular a criação de estratégias eficazes para tornar uma assistência de enfermagem humanizada e de qualidade que atendam as necessidades dos profissionais é urgente.

Como as representações sociais traduzem-se como formas de conhecimento prático que implica nas ações dos sujeitos frente aos objetos que Ihe são dados a pensar, os resultados deste estudo mostram que se faz preciso discutir a Política Nacional de Humanização, suas diretrizes e práticas propostas, à luz das concepções dos profissionais, usuários e gestores, problematizando os elementos que importam à visão peculiar que cada um destes segmentos tem sobre a humanização. Isto porque esta se dá na prática concreta de tais sujeitos.

O estimulo ao debate acompanha-se da necessidade evidenciada de estudos sobre diagnósticos situacionais de campo, já que a humanização também se situa nas condições de oferta dos serviços e do cuidado. Sem condições, torna-se difícil agir em prol de relações interpessoais humanas e solidárias, pois no campo do cuidado profissional, as condições de oferta são inerentes para garantir dignidade aos partícipes do cuidado - usuário e profissional.

Portanto, a presente pesquisa indica pressupostos para que se avance na implementação da $\mathrm{PNH}$ nas práticas assistenciais, justamente por compreender as próprias concepção daqueles que estão cotidianamente no processo de cuidar e ser cuidado. Entretanto é preciso que se aponte que tais resultados não podem ser generalizados haja vista o cenário restrito em que esta pesquisa foi realizada - setor de clínica médica, apresentando-se, portanto como uma limitação do estudo. Por isso é necessário o investimento em investigações futuras acerca da humanização, utilizando a TRS ou outras teorias e metodologias, abrangendo outros cenários hospitalares a fim de confirmar ou confrontar tais resultados.

\section{REFERÊNCIAS}

1. Ferreira J. O Programa de Humanização da Saúde: Dilemas entre o Relacional e o Técnico. Saúde Soc 2005;14(3):111-8.

2. Bermejo JC. Humanizar a saúde: cuidado, relações e valores. Petrópolis, RJ: Vozes; 2008.

3. Campos ACS. Humanização dos cuidados em saúde: conceitos, dilemas e práticas. Cad Saúde Pública 2007;23(4):979-81.

4. Jodelet D. O movimento do retorno ao sujeito e a abordagem das representações sociais. Soc Estado 2009;24(3):679-712.

5. Moscovici S. Representações sociais: investigações em psicologia social. Petrópolis: Vozes; 2003.

6. Moscovici S. A psicanálise, sua imagem e seu público. Petrópolis: Vozes, 2012.

7. Ministério da Saúde. Secretaria executiva. Núcleo Técnico da Política Nacional de Humanização. Humaniza SUS: Humaniza SUS: Política Nacional de Humanização: a humanização como eixo norteador das práticas de atenção e gestão em todas as instâncias do SUS, Brasília, DF: Ministério da Saúde; 2004.

8. Santos Filho SB, Barros MEB, Gomes RS. The National Humanization Policy as a policy produced within the healthcare labor process. Interface Comun Saúde Educ 2009;13(Suppl 1):603-13.

9. Bardin L. Análise de conteúdo. 6. ed. Brasil: Edições 70; 2011.

10. Ferreira MA. A comunicação no cuidado: uma questão fundamental na enfermagem. Rev Bras Enferm 2006;59(3):327-30.
11. Veloso RC, Ferreira MA. Saúde e serviços: relações estabelecidas com os usuários à luz das representações sociais da cidadania. Rev Enferm UERJ 2013;21(1):60-5.

12. Jovchelovitch $\mathrm{S}$. Os contextos do saber: representações, comunidade e cultura. Petrópolis: Vozes; 2008.

13. Rodrigues ILA, Motta MCS, Ferreira MA. Representações sociais de enfermeiros sobre o portador de tuberculose. Acta Paul Enferm 2013;26(2):172-8.

14. Araújo FP, Ferreira MA. Representaciones sociales sobre la humanización de la atención: implicaciones éticas y de la moral. Rev Bras Enferm 2011;64(2):287-93.

15. Andrade MAC, Artmann E, Trindade ZA. Humanização da saúde em um serviço de emergência de um hospital público: comparação sobre representações sociais dos profissionais antes e após a capacitação. Ciênc Saúde Coletiva 2011;16(Suppl.1):1115-24.

16. Chernicharo IM, Silva FD, Ferreira MA. Humanização no cuidado de enfermagem nas concepções de profissionais de enfermagem. Esc Anna Nery Rev Enferm 2011;15(4):686-93.

17. Stumm EMF, Maçalai RT, Kirchner RM. Dificuldades enfrentadas por enfermeiros em um centro cirúrgico. Texto \& contexto Enferm 2006;15(3):464-71.

18. Fontana RT. Humanização no processo de trabalho em enfermagem: uma reflexão. Rev RENE 2010;11(1):200-207.

19. Mendes PW, Castro ES, Ferreira MA. As vertentes do cuidado de enfermagem. Esc Anna Nery Rev Enferm 2003;7(2):239-46.

20. Waldow VR. Cuidar: Expressão humanizadora da enfermagem. 2. ed. Petrópolis: Vozes; 2007. 